\title{
Transferring Culture in Screen Translation - An Analysis of Culture-Specific Elements in Translating English Films into Mandarin for Dubbing
}

\author{
Song Cui ${ }^{1}$ \\ ${ }^{1}$ The Open University of China, Beijing, China \\ Correspondence: Cui Song, Faculty of Foreign Languages, The Open University of China, No. 75, Fuxing Road, \\ Haidian District, Beijing, China (100039). Tel: 86-1360-125-8715. E-mail: cuisong@crtvu.edu.cn; \\ cs8715@yahoo.com
}

Received: February 19, 2013 Accepted: March 17, 2013 Online Published: May 17, 2013

doi:10.5539/ijel.v3n3p115

URL: http://dx.doi.org/10.5539/ijel.v3n3p115

\begin{abstract}
This paper is aimed at applying the theories in translation studies and intercultural communication to the research of the strategies in dealing with the translation of culture-specific elements in film dialogues from English into Mandarin. The aspects of culture including dimensions of communication and the value of collectivism and individualism in Chinese culture and English culture, which might differentiate people's ways of thinking and language use, thus closely related to translation practice, will be examined. Nida's theory on naturalness and Yan Fu's statements on comprehensibility will be studied. Example dialogues extracted from films including Love and Bullets, Heat, For Richer, For Poorer and The Patriot will be analyzed to help conduct the discussion of the possible strategies in transferring culture in screen translation for dubbing, so as to make the translation fluent and natural, and in a style that suits the target language audience's perception.
\end{abstract}

Keywords: screen translation, dubbing, individualism, collectivism, naturalness

\section{Introduction}

Language can be understood as the linguistic representation of culture (Nida, 2001), which reflects the ways in which people of this particular culture live and think, and the ways in which they express themselves and communicate. When translating, it does not seem possible to deal with language without examining the culture in which the language is rooted (Nida, 1956). The aspects of culture discussed in this paper are the dimensions of communication and the content of communication, and two of the major culture-specific elements need to be taken into consideration when doing screen translation: collectivism and individualism (Hofstede \& Hofstede, 2005)

One of the definitions of culture is that culture refers to "all the knowledge and values shared by a society" (DePoy \& Gilson, 2007). Shared knowledge functions as schema that people build their communication upon. This paper focused on the culture-specific issues regarding different ways of communication and different shared background knowledge in the English and Chinese cultures when translating films from English into Mandarin for dubbing. With the limited scope of this paper, the cultural issues such as ideology, politics and religions, and certain language features deeply anchored in culture, such as wordplay, are not discussed. Theories of translation are reviewed to demonstrate the goal of the study of culture and dimensions of communication in screen translation.

\section{Theoretical Backgrounds}

Before the discussion of the possible strategies in dealing with culture-specific elements in screen translation practice, we need to look at some theories of translation and intercultural communication that those strategies, which will be talked about in the next part of the paper, are based upon.

\subsection{Fluency and Naturalness in Western Translation Theories}

Translation for dubbing is often regarded as a strategy of domestication by which translator tries to remove the elements in the source text that appear foreign to the target language audience (Chaume, 2007; Ruiz, 2007), especially those culture-specific elements which might be too foreign for the target audience to understand and 
perceive. When beyond immediate comprehension, foreignness caused by cultural differences in the dubbed version of foreign films will usually depredate the illusion of fiction that films intend to produce. Translation in this case is to substitute the culturally foreign elements with what can be perceivable to the target language audience (Venuti, 1995). The feedbacks from the dubbing directors the author of this paper has been working with for over two decades also confirm that the language used in such translation should be the real language the target audience use in their real life. Venuti also states that "[t]translation is a process by which the chain of signifiers that constitutes the source-language text is replaced by a chain of signifiers in the target language which the translator provides on the strength of an interpretation" (ibid). "In different cultures, the same signifier may introduce different significations, and the same reference may denote different referents. If such difference is not smoothed out in translation, the text in the target language will possibly appear unnatural and awkward to the target language audience, which will, to some extent, ruin the artistic value of the original cinematic works" (Cui, 2012).

Naturalness is one of the two conventions in translation for dubbing identified by Gottlieb (2006, cited in Fresco, 2012), with synchrony as the other one which is not in the scope of discussion of this paper. Nida (1956) has argued that translation should provide the "closest natural equivalence" to the substance of the original, both in meaning and in style, though with the meaning as the first to be considered if the two can not be achieved at the same time. Translation should be dynamically equivalent to the source text so as to bring "complete naturalness of expression" (Nida, 1964), which may relate the target language audience to the communication mode of their own culture.

\subsection{Yan Fu's Focus on Style and Naturalness}

Nida's argument about the attention that translators need to pay to naturalness in equivalence, meaning and style echoes what $\mathrm{Yan} \mathrm{Fu}$ stated as the three standards of translation that translators need to attain, which are xin (faithfulness), $d a$ (comprehensibility) and $y a$ (elegance). In his Preface to Tianyanlun, Yan Fu focused his argument of these standards on comprehensibility. He stated that translation which is not comprehensible can not be reckoned as faithful. The purpose of elegance, in his sense, is to use the pre-Han classic Chinese syntax and style to facilitate "the comprehensibility of the profound principles and subtle thoughts" (Yan, 1901). The modern version of Chinese can hardly provide such comprehensibility (ibid).

What Confucius said, cited by Yan Fu, about the refinement of language reflects that the only acceptable style in writing in the Chinese history up to Yan Fu's age was the refined and elegant style. Thus, Yan Fu's style of "elegance" appeared natural to his intellectual readers during his time. In terms of screen translation today, as often required by the producers and reviewers of the television networks, such as the Movie Channel of China for which the author of this paper has been translating and dubbing, the language style translators choose to use needs to fulfil the purpose of establishing the characters of the film story and needs to be in good tune with the characteristics of the film, which in most cases is not the style that Yan Fu chose to use when translating Tianyanlun, but a style or styles that modern Chinese film goers and TV viewers accept and perceive.

\subsection{The Purpose of Screen Translation}

The purpose of screen translation is to provide the target language audience, namely the Chinese speaking audience in this paper, a facilitated access to the information and entertainment of foreign films (Díaz Cintas \& Remael, 2007). In this sense, what the Chinese speaking audience expects from an English film dubbed in Chinese is not merely the information of a story, but also the entertainment the creators of the original film would like their English speaking audience to enjoy, or as what Mr Chen Xuyi, the prominent screen translator and dubbing director who was active during 1940s to 1980s, said that the translated and dubbed version of the films "should not stop at letting the audience understand the story; the 'taste' of the original film should not be lost." (Li \& Chen, 2007). In other words, translation of English films needs to concern how the Chinese speaking audience may feel about the dialogue, as well as how much they will understand it. That is to say that translation should be perceivable as well as comprehensible, or in Mr Chen's words, be "tasteful" as well as understandable. The translated dialogue should be able to impact the target language audience immediately as the original does to its audience, and the audience should be able to "grasp immediately the sense of the dialogue" (Zatlin, 2005), without any dwelling on guessing or analysing what the dialogue might mean. To achieve such a goal in screen translation, the target language audience's culture in terms of language and communication mode needs to be examined. Although people of different cultures may have the same perception toward different semiotic symbols, for instance a heartfelt smile often conjures up goodwill both in the Chinese culture and the English world, people of different cultures usually have different perceptions toward the same semiotic symbols, since, in terms of language use, "[w]hen users of everyday language articulate specific words, their speech is linked to 
their own perceptions and navigations in their day-to-day reality"(Gertz, Valsiner \& Breaux, 2007). Thus, when people of different cultures have their "day-to-day realities" more or less different from one another, the perceptions linked to their speech must be different. The former, i.e., the same perception toward different semiotic symbols, is what screen translators might like to pursue, and the latter, avoid.

When the culture-specific elements are properly dealt with, the translated version of the film script could have a better chance to achieve fluency and naturalness both in meaning and in style as illustrated by the discussion in the following section of possible strategies. To achieve such fluency and naturalness in dubbing, one of the things we need to do is to investigate the major differences in communication mode between the English language culture and the Chinese language culture.

\subsection{Intercultural Communication Theories that Affect Translation for Dubbing}

Film dialogue involves two levels of communication: the communication between characters in the film and the communication between the film and the audience, with the latter one as the real level of communication (Herbst, 1997), since whatever the characters say in the film is for the audience to hear. Therefore, English-Chinese screen translators need to study the differences in verbal communication between the English language culture and the Chinese culture, and try to convert the English way of communication on the screen to a level that is perceivable to the Chinese speaking audience, especially those who do not speak enough English to understand the original film.

Hall (1976) points out that human communication mode can be categorized into high-context and low-context communication systems. In high-context communication system, convey of message relies mostly on the context or the background knowledge shared by the parties involved in the communication process, whereas in low-context communication system, message is conveyed mainly via explicit verbal codes (ibid). On this scale of high- and low-context communication, Chinese culture appears to be closer to the higher end, while the British and American cultures, the lower end (Ting-Toomey, 1999).

On the other hand, within a culture, even in a low-context culture such as the British and the American ones, when people share the same background knowledge or schema - the "pre-existing knowledge structure in memory" (Yule, 1996), they tend to use high-context communication strategies in their conversations. Some of these schemata are "culturally determined", and regarded as "cultural schemata" (ibid). If the target language culture does not share the same schemata with the source culture in which the film makers and their source language audience are communicating, the information of the film dialogue can hardly be conveyed to the target language audience. Therefore, when translating, translators might need to use the low-context communication strategy to establish a common ground between the target language audience and the source text.

Another dimension of culture which affects screen translation is the individualism-and-collectivism orientation that contributes to cause different communication approaches in different cultures. Although no culture seems to be at either of the extreme ends of the spectrum of individualism and collectivism, Chinese culture appears to be more collectivist, while the British and American cultures, more individualist (Hofstede \& Hofstede, 2005). Neuliep (2003) states that in collectivist culture, "social behaviour" including communication behaviour "is guided by the group", while in individualist culture, "social behaviour is guided by one's personal attitudes, motivations, and other processes". According to Ting-Toomey (1999), individualism accentuates individual identity, while collectivism emphasizes group identity, where individual is usually identified by their position in a group and their relation with other group members. For example, a girl may say "I am the third daughter in my family" to describe who she is (ibid). This difference between cultures contributes to the difference in expressions used to refer to self, as shown in the above example, and the others. It seems obvious that translators may need to take this dimension of culture into consideration when translating relevant expressions in film dialogues, so as to help the target language audience avoid making any associations other than what the original dialogue writers intend to imply, and some possible strategies will be discussed in the following section of this paper.

\section{Possible Strategies}

When differences in ways of communication between the English language culture and the Chinese culture pose to be obstacles for the Chinese speaking audience to appreciate the English films, strategies need to be implemented to remove such obstacles, and this has been constantly required by the dubbing directors the author of this paper, as a screen translator for more than two decades, has been working with. When translating printed material, such as novels, there is always possibility to add footnotes to provide explanations of culture-specific elements that might sound unnatural in the target language, and there is always space under the pages or at the 
end of the books to accommodate the notes. In screen translation for dubbing, however, there is usually no room for "footnotes". Though technically, captions of explanatory messages can be put on any corner of the screen to annotate the dubbed dialogue, the fact is that this is not applicable in the dubbing industry in China. In all the ninety films translated by the author of this paper for Movie Channel of China and local television stations, and over five hundred films and TV dramas he has took part in dubbing, no captions functioned as footnote has ever been used on the screen of any dubbed films. Though it can be found in some fansub films where notes are put in parenthesis under the dialogue subtitle or on the top of the frame, putting notes to the translation for dubbing is not a common practice in mainland China's mainstream media, i.e., on television and in cinemas in the context of screen translation. Strategies have to be applied to transfer expressions of the source language culture into the ones that the target language dubbing actors and audience find natural, perceivable and expressive.

Among the possible strategies, there are:

\subsection{From Low-Context to High-Context}

One of the stigmas of "a bad translation" is the "[a]wkward and unnatural syntax and sentence structure, often based on the syntax of the source language" (Baker \& Jones, 1998). Thus, in some cases, an explicit expression in English, which belongs to a low-context communication mode, may sound strange and awkward when translated into Chinese literally. Obviously this also applies to the translation of film scripts for dubbing in which case the translation is heard, and the language used in the translation is usually expected to sound natural, perceivable and expressive (Gao, 2012). Therefore, translators may need to shift the low-context communication approach in English to a higher one to suit the Chinese way of expression, while keeping the meaning and function of the original dialogue undistorted. For instance, in Chinese, more than in English, expressions of gratitude and appreciation could vary from context to context, and sometimes in a more indirect way ( $\mathrm{Li}, 2007)$, and in Chinese context, speakers do not say xiexie ni de... (Thank you for your...) as much and often as speakers in English context do, as shown in the following example.

In a scene of the film Love and Bullets (dir. Rosenburg, 1979), Jackie (Jill Ireland) and Charlie (Charles Bronson) are at a cottage in a snowy mountain when a killer comes with an intention of a sneak attack on Charlie. Jackie screams to warn Charlie who is cutting firewood outside. It turns out that, thanks to Jackie's warning, Charlie survives the killer's attack and finishes him. Then, Charlie comes back into the cottage and says to Jackie, "Thank you for your warning." The literal Chinese translation of this line, which is xiexie ni de jinggao, appears to be foreign and unnatural to the Chinese ears. In such a situation, the following expression in Chinese may work better for the purpose of making the line sound more natural and perceivable.

$\begin{array}{rrrr}\text { gangcai } & \text { duo } & \text { kui le } & n i \\ \text { just now } & \text { much } & \text { owe } & \text { you }\end{array}$

(What happened just now owes to you much.)

In English, "Thank you for your warning" is an explicit expression, and almost no context is required to understand what Charlie thanks Jackie for - the warning. However, in Chinese, the sentence "gangcai duo kui le ni" (just now much owe you) does not tell explicitly what owes to you much. But with the phrase "gangcai" (just now), it is clear that there is a piece of information contained in the context, which means one needs to know what happened just now so as to understand what owes to you. In other words, if what happened just now is known to both parties of the communication, it is not necessary to mention it when expressing thankfulness. It can be regarded as an equivalence to "Thank you for your warning" in English dynamically on the sense-to-sense basis, rather than on a word-for-word level. This strategy which brings a low-context communication approach to a high-context one can, to a certain degree, make the translation sound natural and fluent in the target language, namely Mandarin in the context of this paper.

\subsection{From High-Context to Low-Context}

Sometimes, translators may find themselves in a situation that the dialogue of a film adopts a high-context communication approach, when literal translation might sound confusing to the target language audience, as shown in the following example. Part of the information of a dialogue is omitted since the background knowledge is shared by the characters of the story and the English speaking audience. Such omission usually makes the literal translation of the dialogue unintelligible to the Chinese speaking audience. In this case, it can be argued that the strategy of bringing the high-context mode to a low-context one by adding the omitted 
information back into the dialogue should be implemented to make the meaning of the dialogue explicit and intelligible to the target audience. For example, in Heat (dir. Mann, 1995), when Neil (Robert De Niro) first meets Eady (Amy Brenneman), in their conversation, Eady mentions a store:

\section{EADY}

I've seen you in the store from time to time.

\section{NEIL}

What store?

\section{EADY}

Hennessey and Ingalls. I work there.

The transliteration of the name of the bookstore "Hennessey and Ingalls" will be a string of sounds without any meaning in Chinese. And usually, in Chinese context, when asking questions like "What store?", the enquirer will usually expect an answer indicating what kind of store it is. In this case, when translating, a possible solution is to add shudian (bookstore) into Eady's answer. The Chinese transliteration of the names would be xuan ni shi for Hennessey and ying ge er si for Ingalls. It appears that the Chinese version contains a number of syllables similar to the English version, but it will take longer time for the Chinese dubbing actress to utter xuan ni shi ying ge er si than it does in English. That is to say, the seven syllables in Chinese need more lip movements to utter than "Hennessey and Ingalls" in English, since in spoken English, liaison is a common feature, and sometimes appears to be an elision of sounds (Yao, 2008), which will make the utterance of the phrases shorter than without liaison. While by the common practice of the Chinese dubbing, every syllable of every word must be uttered clearly ( $\mathrm{Su}, 2005)$, and no liaison is accepted. Thus, the same amount of syllables will take longer time and more lip movements to pronounce in Chinese dubbing than in the original English dialogue. When adding shudian (bookstore) into it, the line will be even longer. It makes lip synch impossible when dubbing. To reduce the length of the line so as to make it applicable for dubbing, only the initials of the names "Hennessey and Ingalls", in Chinese xuan ying, are used. The line is shortened into a four-syllable phrase, which is xuan ying shu dian (Hen-In bookstore), so as to make it clear to the Chinese speaking audience that the store where Eady works is the bookstore that Neil goes to in the last scene, and in the meantime, make it feasible to dub.

\subsection{From Individualistic to Collectivistic}

As mentioned earlier in this paper, Chinese culture tends to be more collectivistic, while English culture, individualistic. One of the results of being collectivistic is that in Chinese the position one holds in a group is more sensitive in dealing with their relation with others, and affects their ways of communication, whereas in English, the relation between people, and thus their ways of communication, tends to be more in an individual-to-individual mode rather than position-to-position. As the above-mentioned example illustrates that in the traditional Chinese culture, a girl may introduce herself by telling she is "the third daughter in her family" (Ting-Toomey, 1999), i.e., a position among all the children of the family, rather than her name, which is her individual identity with no implication of whatever position she might hold. When there are dialogues involving such an issue, translators may need to convert the individualistic way of communication in English into a more collectivistic way in Chinese, so as to make the lines which would be uttered by the dubbing actors in Chinese sound natural to the Chinese speaking audience. For example, in the film For Richer, For Poorer (dir. Sandrich, 1992), Aram (Jack Lemmon), the father, a self-made millionaire who starts his business from scratch and now owns a chain of stores, is irritated by his son Michael (Jonathan Silverman), who just graduates from college, and indulges himself with the comfortable life his father builds for him, with no plan to work at a job. In a quarrel between the father and the son, Aram is extremely angry and disappointed at Michael. He yells to Michael, "Get out! Get out of my life!", and drives Michael out of his house. In English, "You get out of my life" appears to emphasize that the relation is over between you and me, who are two individuals. Without a context, the audience may not know what relation between you and me is. However, in Chinese, the relation between a father and a son is normally emphasized in this case. It is not merely a relation between two individuals but two members of a group, namely "a family" in this context. Therefore, a possible translation which may sound more 
natural in Chinese than literal translation of this line could be:

wo meiyou ni zhege erzi
I don't have you this son
(I don't have a son like you!)

In this translation, the relation between a father and a son is accentuated. It does not only sound natural to the Chinese speaking audience, but also, in Chinese context, better expresses the father's anger and disappointment at his son than a word-for-word translation, which may sound foreign and less expressive.

\subsection{From Specific to Generic}

"Common ground is meant the aspects of background knowledge that are taken for granted and shared by a speaker and an addressee in communication. The knowledge involved includes contextual knowledge, linguistic knowledge, and real-world knowledge" (Huang, 2012). In screen translation, these three aspects of knowledge are intertwined to form an overall background knowledge that may or may not be shared by the source language audience and the target language audience. When background knowledge becomes an issue in the film and is not shared by the target language audience, it may cause misunderstanding or difficulty in comprehending the translation if it is done literally.

One of the strategies in dealing with this issue might be to use generic expressions in the translation to replace the specific expressions in the source text, so as to bring the "background knowledge" embedded in the translated expressions to a level that may have higher possibility of being shared by the target language audience. For instance, it is assumed (Note 1) that the generic term yin di an ren (the Native Americans, or the American Indians) is well known to the Chinese speaking audience, but a specific Native American tribe may not be as popular. Here is an example to illustrate it.

In the film The Patriot (dir. Emmerich, 2000), both the words "Indians" and "Cherokees" are used to refer to those Native Americans who allied with the French during the American Revolution. It might be clear for the American audience, who might have the knowledge of who Cherokees are. But it can be assumed that to a certain number of the Chinese speaking audience in China "Cherokee" is more of a model name of Jeep than a Native American tribe. According to the dubbing director and the dubbing actors in the studio when this film was being dubbed, if the Chinese translation of both "Indians" and "Cherokees" are used in the dubbing, it might cause confusion and the audience who do not have the background knowledge of who Cherokees are might possibly think that they are different peoples, or they might need a moment to make the association by themselves that the Cherokees are the "Indians". This moment of effort in trying to understand could pose a distraction for the audience when watching the film. In this particular film, both "Indians" and "Cherokees" refer to the same Native American tribe, therefore in the Chinese translation it will not be likely to make any confusing denotation when using the generic term "Indians" (yin di an ren) to refer to the Cherokees.

\section{Conclusion}

Due to the differences between the English language culture and the Chinese culture in terms of communication mode, individual and group identity, and cultural schemata, what sounds natural in English might not sound likewise if translated into Chinese literally. With the study of the relevant theories of translation and certain features of both the source and the target cultures, it is possible, to a certain extent, to transfer culture from English into Chinese in screen translation with strategies dealing with the culture-specific elements. The purpose of cultural transfer, which should not be implemented at the expense of distortion of meaning, is to make the translation fluent and natural, and in a style that suits the target language audience's perception.

\section{References}

Baker, C. R., \& Jones, S. P. (1998). Encyclopedia of Bilingualism and Bilingual Education. NY: Multilingual Matters, Ltd.

Chaume, F. (2007). Dubbing practices in Europe: Localisation beats globalisation. In A. Remael, \& J. Neves (Eds.), A tool for social integration? (pp. 203-217). Antwerp: Hogeschool Antwerpen, Hoger Instituut voor Vertalers en Tolken.

Cui, S. (2012). Creativity in Translating Cartoons from English into Mandarin Chinese. The Journal of Specialised Translation, 2012(17), 124-135. 
DePoy, E., \& Gilson, F. S. (2007). The human experience description, explanation and judgment. Maryland: Rowman \& Littlefield Publishers.

Díaz Cintas, J., \& Remael, A. (2007). Audiovisual translation: Subtitling. Manchester, UK \& Kinderhook (NY), USA: St. Jerome Publishing.

Fresco, P. R. (2012). Dubbing Dialogues Naturally: A Pragmatic Approach to The Translation Of Transition Markers In Dubbing. MonTI, 4, 181-205. http://dx.doi.org/10.6035/MonTI.2012.4.8

Gao, S. (2012). The Special Characteristics of Film Script Translation. Film Literature, 8, 145-146.

Gertz, S. H. K., Valsiner, J., \& Breaux, J. P. (2007). Semiotic Rotations: Modes of Meanings in Cultural Worlds. NC: Information Age Publishing.

Gottlieb, H. (2006). Constraints, Conventions and Conflicts in Screen Translation. Paper presented at MuTra 2006 - Audiovisual Translation Scenarios (University of Copenhagen, 1-5 May 2006).

Hall, E. T. (1976). Beyond culture. Garden City, New York: Anchor Press/Doubleday. http://dx.doi.org/10.2307/3103266

Herbst, T. (1997). Dubbing and the dubbed text - style and cohesion: Textual characteristics of a special form of translation. In A. Trosborg (Ed.), Text typology and translation (pp. 291-308). Amsterdam and Philadelphia: John Benjamins Publishing Company.

Hofstede, G., \& Hofstede, J. (2005). Cultures and organizations: Software of the mind. New York: McGraw-Hill.

Huang, Y. (2012). The Oxford Dictionary of Pragmatics. Oxford: Oxford University Press. http://dx.doi.org/10.1016/j.pragma.2012.02.006

Li, L. (2004). On the Speech Act of "Thanks" in Chinese. Hubei Social Science, 9, 93-95.

Li, S., \& Chen, Y. (2007). Translated and Dubbed Films: Searching Spring in Autumn. China Pictorial, 9, 56-71.

Neuliep, J. W. (2003). Intercultural communication: A contextual approach. Boston, New York: Houghton Mifflin Company.

Nida, E. A. (1956). Principles of translation as exemplified by Bible translating. In Language structure and translation: Essays by Eugene A. Nida (pp. 24-46). Stanford, California: Stanford University Press.

Nida, E. A. (1964). Toward a science of translating: With special reference to principles and procedures involved in Bible translation. Leiden: Brill.

Nida, E. A. (2001). Contexts in translating. Amsterdam/Philadelphia: John Benjamins Publishing Company.

Ruiz, V. M. G., \& García, L. C. (2007). Other voices, other room? The relevance of dubbing in the reception of audiovisual products. In A. Remael, \& J. Neves (Eds.), A tool for social integration? Audiovisual translation from different angles (pp. 219-233). Antwerp: Hogeschool Antwerpen, Hoger Instituut voor Vertalers en Tolken.

Su, X. (2005). My Career of Dubbing. Shanghai: Wenhui Press.

Ting-Toomey, S. (1999). Communicating across cultures. New York \& London: The Guilford Press.

Venuti, L. (1995). The translator's invisibility: A history of translation. http://dx.doi.org/10.4324/9780203360064

Yan, F. (1901). Preface to Tianyanlun. In L. T. Chan (Ed.), Twentieth-century Chinese translation theory (pp. 69-71). Amsterdam/Philadelphia: John Benjamins Publishing Company.

Yao, H. (2008). An Interview Study of Native Chinese-speaking English as a Foreign Language University Students Experience of Acquiring English Pronunciation. MI: ProQuest Information and Learning Company.

Yule, G. (1996). Pragmatics. Oxford: Oxford University Press.

Zatlin, P. (2005). Theatrical translation and film adaptation: A practitioner's view. Clevedon, Buffalo, Toronto: Multilingual Matters Ltd.

\section{Note}

Note 1. In day-to-day translation practice, translators may not have the time to check for every reference which supports their understanding of their own culture (i.e., the target language culture). The understanding of what is known as background knowledge to the target language audience in general and what is not is usually and pragmatically based on their general assumption gained by living the culture. 